[Downloaded free from http://www.conservationandsociety.org on Tuesday, May 24, 2011, IP: 129.79.203.202] || Click here to download free Android application fo journal

Conservation and Society 9(1): 65-79, 2011

$\underline{\text { Article }}$

\title{
Strangers in Their Own Land: Maasai and Wildlife Conservation in Northern Tanzania
}

\author{
Mara J. Goldman \\ Department of Geography, University of Colorado-Boulder, Boulder, CO, USA \\ E-mail: Mara.goldman@colorado.edu
}

\begin{abstract}
Despite dramatic transformations in conservation rhetoric regarding local people, indigenous rights, and communityoriented approaches, conservation in many places in Tanzania today continues to infringe on human rights. This happens through the exclusion of local people as knowledgeable active participants in management, policy formation, and decision-making processes in land that 'belongs' to them and on which their livelihoods depend. In this paper, I focus on a relatively new conservation area designed on the Conservation Trust Model-Manyara Ranch in Monduli district in northern Tanzania. I present this case as a conservation opportunity lost, where local Maasai who were initially interested in utilising the area for conservation, have come to resent and disrespect the conservation status of the area, after having lost it from their ownership and control. I illustrate how the denial of Maasai memories, knowledge, and management practices in Manyara Ranch threaten the future viability of the place both for conservation and for Maasai use. The paper contributes to a growing literature as well as a set of concerns regarding the relationship between conservation and human rights.
\end{abstract}

Keywords: conservation, human rights, participation, Maasai, Manyara Ranch, Tanzania

\section{INTRODUCTION}

"It's no wonder this area was taken by the wazungu (white people)", Neserian said, looking around her, shaking her head in awe. It was spectacular. It was, in her eyes, 'Maasai heaven'. ${ }^{1}$ Neserian was a Maasai friend from the foot of the escarpment near Lake Manyara. We had come to visit our friend Michael, a Maasai resident of the Ngorongoro Conservation Area. We were sitting outside his home, which rested on the sloping hills of the Ngorongoro highlands. It was the short dusk of the equator day, when a calm falls over the land - cattle walk full and happy back into the kraal for the night, and smoke begins to escape from the roofs of the small mud houses as the women begin their fires for tea. At this time of day, in this place in

\begin{tabular}{|l|l|}
\hline \multicolumn{2}{|c|}{ Access this article online } \\
\hline Quick Response Code: & Website: \\
\hline & www.conservationandsociety.org \\
\cline { 2 - 3 } & \\
\hline
\end{tabular}

northern Tanzania it seems that everyone-whether Maasai or Mzungu - feels they have been blessed with a glimpse of heaven. Neserian's statement reflected more than the beauty and contentment she felt sitting in this place at dusk. Her statement reflected the reality of an ideal Maasai place in the world-for people and livestock. Ngorongoro has the treasured lowland pastures, watered only by the rains, but full of nutritious and tick-free grasses that keep cows fat and healthy. And there are the highlands, where water flows year round, and people and cattle can stay content and full until the next rain. There is also a great diversity of trees. During our walk to the boma, ${ }^{2}$ Neserian kept stopping to marvel at the trees from which walking sticks are carved and valuable medicines are harvested. And there was all that wildlife she had seen earlier in the day, when we had driven into the crater. Ngorongoro, it seemed, had it all.

It should be no surprise, as Neserian pointed out, that wazungu also found Ngorongoro special; so special that they wanted to assure it was protected so that their grandchildren could also experience it. Ngorongoro has become a World Heritage Site, an area of international conservation concern, and a source of national pride and foreign exchange for the Tanzanian State. Protection for the Ngorongoro Conservation

Copyright: (C) Mara J. Goldman 2011. This is an open access article distributed under the terms of the Creative Commons Attribution License, which permits unrestricted use and distribution of the article, provided the original work is cited. 
[Downloaded free from http://www.conservationandsociety.org on Tuesday, May 24, 2011, IP: 129.79.203.202] || Click here to download free Android application fo journal

\section{6 / Mara J. Goldman}

Area is supported by international organisations like the International Union for the Conservation of Nature (IUCN), the Frankfurt Zoological Society (FZS), and the United Nations Educational, Scientific, and Cultural Organization (UNESCO). It is one of the main tourist attractions in Tanzania. As such, Ngorongoro no longer belongs to the Maasai; it belongs to the state, and to the world. Maasai have, in fact, become strangers in their own land.

Maasai from other areas outside Ngorongoro, including the place where Neserian lives, have a story they tell to explain how it came to be that Maasai in Ngorongoro lost their rights to use their land as they please, particularly their right to farm. The story goes something like this: ${ }^{3}$

Long ago [opa] there were two Maasai leaders [ilaigwenak], one from Kisongo and one from Ngorongoro. They were presented [by wazungu] with two bags and asked to choose one. One bag was filled with money, the other filled with dirt. The Ngorongoro Maasai chose the bag filled with money. The Kisongo Maasai chose the bag filled with dirt. That is why the Ngorongoro Maasai do not have the freedom to farm their land. They chose money and gave away their land. The Kisongo Maasai, however, can farm as they want and have not suffered from the loss of their land for conservation as the Maasai in Ngorongoro have. The Kisongo Maasai still have their land. ${ }^{4}$

Michael laughs when he hears this story, and insists they never received money for their loss. Perhaps what is still more ironic is the fact that Maasai throughout much of Tanzania have lost rights over land that was once considered theirs - even those who tell this story, as illustrated below. But it is not just loosing land or being evicted from one's home that is at stake, for Maasai are still (at least for now) legally allowed to reside inside the Ngorongoro Conservation Area. They have, however, been marginalised from decisions regarding its use and management, all of which impact their livelihoods. ${ }^{5}$ This has made Maasai throughout Tanzania strangers in their own land, whenever conservation concerns are involved. Despite dramatic transformations in conservation rhetoric towards community-based approaches, conservation in Maasai areas of Tanzania today continues to infringe on human rights in two specific ways: through the eviction of families and the destruction of property; and through the exclusion of Maasai as knowledgeable participants in decision-making processes in land that 'belongs' to them, on which their livelihoods depend, and on which they sometimes continue to reside. This second form of exclusion can also be seen as economic exclusion, since Maasai rarely benefit economically from conservation tourism, while having their own economic activities limited, e.g., farming. ${ }^{6}$

In this article, my focus is on this second form of exclusion, related to a relatively newly established conservation area designed on the Conservation Trust Model $^{7}$ - Manyara Ranch in Monduli district in northern Tanzania (Figure 1).
Here, evictions were not central to the establishment of the conservation area, yet exclusion still occurs. Through ethnographic research findings, I illustrate how local claims to land and history in Manyara Ranch as well as local knowledge and use-rights have been marginalised. I present Manyara Ranch as a conservation opportunity lost, where local Maasai who were initially interested in utilising the area for conservation, have come to resent and disrespect the conservation status of the area, after having lost it from their ownership and control. The paper contributes to a growing literature and set of concerns regarding the increasingly precarious relationship between conservation and human rights.

\section{CONSERVATION AND HUMAN RIGHTS: SETTING THE TONE}

There have been a series of articles in conservation-related journals focused on the human rights abuses of conservation (Adams et al. 2004; Brockington \& Schmidt-Soltau 2004; Agrawal \& Redford 2006; Brockington \& Igoe 2006; Brockington et al. 2006; Redford \& Sanderson 2006; West et al. 2006; Rangarajan \& Shahabuddin 2006; Igoe 2007; Igoe \& West 2007). The focus has been predominately on the impact of conservation-related evictions on the rural poor, and the idea that conservation should contribute to development and poverty alleviation. Additional work has focused on the neoliberalisation of conservation leading to a disconnect between human rights and conservation, as new spaces of investment are promoted over the needs of local communities, and the state is no longer trusted to provide for and protect its citizens (Igoe 2007; Igoe \& Croucher 2007). This debate has understandably stirred reactions from the conservation community, prompting further dialogue from social scientists, and exposed what some see as a disconnect between fixed (and passionate) positions on both sides (Agrawal \& Redford 2009; Redford \& Brosius 2006; Peterson et al. 2010). Agrawal \& Redford (2009: 56) suggest that emotions get mixed with data and the lack of data when concerns of human welfare are seen to "rub up against those of conservation". Yet, the debate does offer promise for continued dialogue across the rough waters of disciplinary and advocacy divides.

There are some key points that have remained peripheral to this debate, partly due to the particular focus on displacements. These include the importance of memory and history associated with the making and framing of new conservation areas, and the participation of local communities in conservation-related decision-making once a conservation area is established. I take up both these points, with a focus on the importance of closing what I call a participation gap. I am referring here to the missing participation of local people in 1) historicising conservation areas (including memories of nature-society relations in a place), and 2) contributing to the management of conservation areas (including knowledge contributions). In addition to being a human rights issue, this participation gap can be detrimental for conservation. 
[Downloaded free from http://www.conservationandsociety.org on Tuesday, May 24, 2011, IP: 129.79.203.202] || Click here to download free Android application for journal

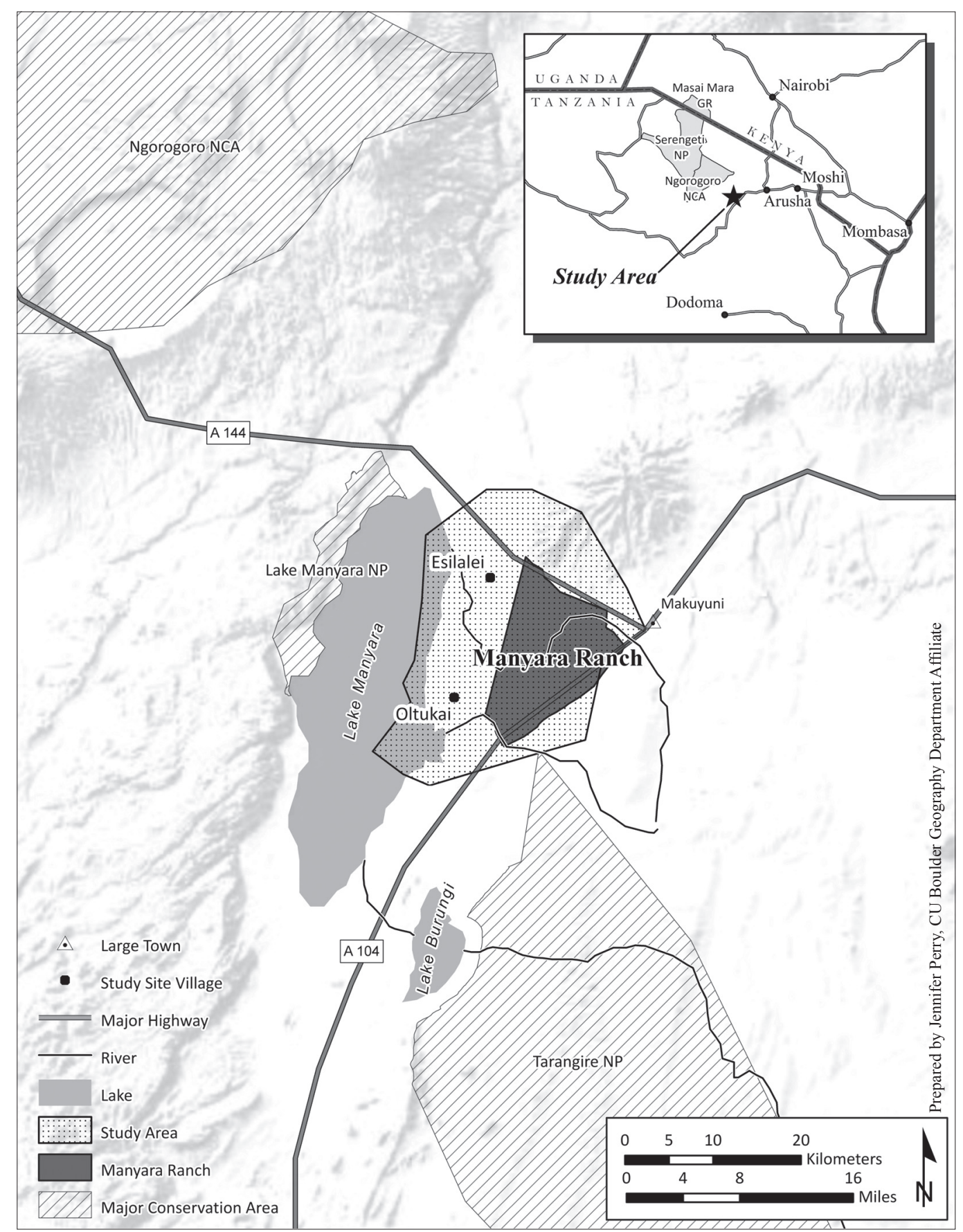

Figure 1

Map of the study area

\section{History and Memory}

History matters, but what gets considered legitimate history also matters. It matters from a human rights perspective in terms of respecting ancestral claims to land, resources, and spiritual sites. It matters for conservation in terms of understanding the complex ecologies sought for protection. Hughes (2007) takes issue with the lack of history in recent discussions of human rights' abuses through displacements for conservation. She argues that these analyses often confuse memory with history. Social memory, she contends, is highly political and linked to historic and contemporary struggles. Social memories, particularly those presented for public consumption, do not always reflect accurate historical moments. Communities may make public claims that they were evicted for conservation even if this was not the case, because such claims carry political leverage and are often close enough to a wider accepted truth to warrant little investigation. Hughes provides the Maasai Mara as a case in point. While a widely accepted truth in Kenya sees Maasai as being removed by force for the creation of protected areas across the country, in reality they were not evicted from the area where the Mara 
[Downloaded free from http://www.conservationandsociety.org on Tuesday, May 24, 2011, IP: 129.79.203.202] || Click here to download free Android application fo journal

\section{8 / Mara J. Goldman}

reserve is today, and moreover they did not actually reside there as it was tsetse fly infested bush. ${ }^{8}$ Yet today Maasai activists and politicians often discuss the Mara as lost to the Maasai through forced displacement for conservation. Hughes does not say that memories do not count. She acknowledges that Maasai have suffered severe land loss in Kenya, and that the socio-economic, cultural, and psychological costs of such losses are staggering. Yet, Hughes (2007: 322) warns:

[W]e should also beware of the role played by both settler and indigenous African imaginings of landscape and loss. We cannot assume all displacement from protected areas was coerced, just because politicians and pundits say so, or that forced removals took place at all in order to create certain parks.

Following Hughes (2007), I suggest that we need to take history seriously, while recognising that certain histories are constructed to project particular versions of the present. But history is not just about displacement, and claims to a place do not demand permanent residency. Local memories are important for understanding the value, use, and history of particular places - to the local community and in terms of larger questions of ecological change. Conservation areas are often created alongside a narrative projecting them as historically pristine places (Brockington 2002). It is important to uncover the truth that people often lived in these places, with forced evictions needed to create the façade of pristine nature. ${ }^{9}$ However, it is equally important to know when forced evictions did not occur, yet local memories of an area are ignored and use-rights are interrupted. In the case I present below, people were not evicted by force from the area that became Manyara Ranch; Maasai 'gave it away', because it was tsetse fly infested bush. When it became an official conservation area half a century later, the few evictions that occurred inside Manyara Ranch boundaries were of already illegal settlements. Yet local Maasai never stopped using the area to meet livelihood and cultural needs. Historically, Maasai did not view land as exclusive private property. They learned the hard way, when they gave land for use to outsiders and then lost it forever from their larger system of resource access.

\section{Participation and Local Knowledge}

The very participation of local 'communities' 10 in decisionmaking processes regarding land and other resources that directly impact their livelihoods should be recognised as a basic human right. The façade of participation is not enough, as is the common practice of requesting consent for projects that remain wholly managed in a top-down manner. The need for local people to participate in conservation projects is not a new argument; it has been central to debates over community-based endeavours (Hulme \& Murphee 2001). The widespread neoliberalisation of conservation is creating new spaces of participation - by local communities, transnational conservation agencies, and the private sector - in complex and often compromising ways (Gardner 2007; Igoe 2007). As I have argued elsewhere, such endeavours often are a lot less about participation than about the spread of conservation (Goldman 2003). Yet active participation in the processes of knowledge construction, decision-making, and management planning should be recognised as a basic human right, especially when outcomes have potentially far-reaching impacts on the lives and livelihoods of those involved.

Participation of different communities in conservation planning can do more than meet basic human rights obligations and placate local populations into accepting conservation. It can actually be good for conservation and for maintaining the ecological integrity of an area. This is because 1) local knowledge often provides detailed understandings of ecological processes, 2) the inclusion of local knowledge increases the diversity of knowledge contributions to problem solving and management decision-making (Gadgil et al. 1993; Igoe 2002; Nadasdy 2003), ${ }^{11}$ and 3) local control of resources is often associated with respect and improved management of said resources.

I am, therefore, echoing what several others in this debate have said in different ways - that we should not have to choose between conservation and people. I am suggesting that a participation gap is bad for conservation and for local communities; it represents human rights abuses and poses ecological threats to conservation. Participation by local people in conservation may provide new insights and strategies for conservation, which do not separate people from nature in the strict dichotomous way western conservation models do. ${ }^{12}$ The exclusion of local people, on the other hand, can result in deliberate (if illegal) misuse of resources or passive neglect of an area, once it is no longer seen as belonging to the community. ${ }^{13}$

I explore these points by looking at Manyara Ranch in northern Tanzania. Today, Manyara Ranch is in the hands of the Tanzanian Land Conservation Trust, to be run as a conservation 'trust' on behalf of the communities to which it originally belonged. But as we shall see, communities remain peripheral to its management and are restricted in its use. Their own views of the history of the area are ignored, leaving little room for contributions on present management, and threatening the future of Manyara Ranch for Maasai, their cattle, and wildlife.

\section{METHODS}

Findings presented here are based on five years of ethnographic data collection in the area (2002-2004, 2005, 2007, 2009). This includes short interviews with household $(\mathrm{HH})$ heads in a sample of bomas in both villages (2003; $n=43$ ), long openended interviews regarding local ecology and land management with a non-random sample of elders (men and women) familiar with history and ecology of the area (2003; n=20), participant observation of regularly planned and 'emergency' Manyara Ranch steering committee meetings (2002-2004), and ethnographic observations, formal and informal conversations with villagers, steering committee members, employees of 
[Downloaded free from http://www.conservationandsociety.org on Tuesday, May 24, 2011, IP: 129.79.203.202] || Click here to download free Android application for journal

Manyara Ranch and African Wildlife Foundation (AWF, a US-based international wildlife conservation NGO behind the Tanzanian Land Conservation Trust), and members of the Tanzanian Land Conservation Trust board of trustees, throughout all years. All interviews, observations, and informal conversations for this paper were translated into English by the author, often with the help of an assistant from Maa into Swahili first. Interviews and meetings were often recorded and then transcribed by the author for further analysis.

\section{MANYARA RANCH: A CONSERVATION OPPORTUNITY LOST?}

If the communities perceive that these (conservation) Trust Lands are simply the first step in a move to make them national parks, preserves, or wildlife management areas, then this innovative attempt to establish a Trust Land will not succeed and a great opportunity will be lost (African Wildlife Foundation 2000: 11).

Formerly a state-run cattle ranch, Manyara Ranch was prioritised for privatisation in the late 1990s, as part of the liberalisation of the Tanzanian economy. Manyara Ranch has an area of 17,807 ha. and sits in the middle of what AWF refers to as the Maasai Steppe Heartland in Northern Tanzania (Sumba et al. 2005; Figure 1). When the land was announced to go up for sale, residents of Esilalei and Oltukai villages formally requested that the Tanzanian president return the land to them as the original owners. However, the land in question was recognised as part of an important, and threatened, wildlife corridor (Goldman 2009). AWF and others presented this 'corridor' as essential to the survival of migratory wildlife populations in the area, impacting the ecological viability of both Tarangire National Park and Lake Manyara National Park, two of the highest income earning parks for the Tanzanian State (Sachedina 2008). For this reason, many people were not prepared to see Manyara Ranch lost to private hands and were concerned about it being given unconditionally (i.e., with no regulations on its use) to villagers. Just like Ngorongoro, Manyara Ranch was presented as too important and too special to be trusted with local people, despite their recognised claims of ownership.

AWF worked with village representatives to plan together for the future of the area - both to recognise local ownership rights and assure conservation interests. At the same time and with the help of other international conservation organisations, and the local Member of Parliament, AWF lobbied the Tanzanian state to sell them Manyara Ranch in 2000, under the auspices of the newly formed Tanzanian Land Conservation Trust. ${ }^{14} \mathrm{~A}$ 99-year lease was obtained with funding from the United States Agency for International Development (USAID) (Sachedina 2008), in the name of the Tanzanian Land Conservation Trust, which is run by a board of trustees and a steering committee. The Chairman of the Board is the local Member of Parliament, who at the time was also the minister of livestock and water. $\mathrm{He}$ then became the Prime Minister of the country from December
2005 to February 2008..$^{15}$ The rest of the board comprises 'experts' from the fields of wildlife, livestock, and tourism, including representatives from AWF, World Wide Fund for Nature, Tanzanian National Parks Authority, United Nations Development Program, and the private sector. The steering committee comprises village government representatives. There is one village representative on the Tanzanian Land Conservation Trust Board, who does not speak or understand English or Swahili - the languages used at board meetings. ${ }^{16}$ The Trust deed stipulates that the board is to work with the steering committee, to manage the land, which is to be held in trust and managed for conservation on behalf of the villages of Esilalei and Oltukai.

AWF's interest in Manyara Ranch is connected to a larger goal of creating a new form of conservation in Tanzania, based on the Nature Conservancy's Land Trust concept, to further their 'heartland' approach to conservation. Heartlands are AWF's version of landscape scale conservation (African Wildlife Foundation 2005; Goldman 2009); anchored in protected areas, but connected to human-occupied spaces across a 'landscape' that is deemed valuable for conservation. Land Trusts provide a mechanism through which to acquire lands recognised as important for conservation but outside of the protected area system and therefore threatened by 'development' (African Wildlife Foundation 2005; Sachedina 2008). According to AWF, "the Tanzanian Land Conservation Trust manages these lands to protect the needs of pastoral communities as well as to preserve the integrity of these areas for wildlife conservation" (http://www.awf. org/content/solution/detail/3505. Accessed 3 May 3, 2010). Manyara Ranch was the first Tanzanian Land Conservation Trust purchase. As the first conservation trust of its kind in Tanzania, Manyara Ranch is heralded as an important step towards creating community-friendly conservation, by mixing conservation with livelihoods ${ }^{17}$.

Manyara Ranch is promoted as AWF's flagship 'conservation enterprise' (Sachedina 2008). However, as illustrated by the above quotation, AWF is aware of the challenges they face in creating a new form of conservation that local communities will not resent. They are aware of the history of land loss for conservation that Maasai have suffered, and the fears local people have regarding any 'new' conservation project. Land Trusts, therefore, need to be different from the 'fines and fences' approach of national parks, or they will loose local support and become a 'conservation opportunity lost'. Maasai initially welcomed Manyara Ranch as a jointly-run conservation area, which they thought they owned. However, today, they resent what they see as an outside-run conservation area on land taken away from them.

\section{History and Belonging}

In 2003, the first manager of Manyara Ranch decided the area should have a new name that reflected its new role as a community-based multiple-use conservation area. ${ }^{18}$ In a show of good faith, he asked local Maasai to suggest a name. They 
[Downloaded free from http://www.conservationandsociety.org on Tuesday, May 24, 2011, IP: 129.79.203.202] || Click here to download free Android application fc journal

proposed Ramat, a Maasai word that encapsulates the very meaning of stewardship: to care for and look after-livestock, people, wildlife, the environment; it is the same name used by Maasai in Ngorongoro Conservation Area for the Ngorongoro Highlands. The American donor community, however, rejected the name because Ramat sounded too Arabic, and thus seemed a risky choice for a USAID funded project in east Africa during the 'war on terror'. ${ }^{19}$ Today the area continues to be called Manyara Ranch, although most local Maasai refer to it as Alchamba, a Maasai version of the Swahili word shamba, meaning farm. This name reflects the history of the area, known by local Maasai residents, as being cultivated (maize and beans) by previous owners. Another name used to refer to Manyara Ranch headquarters is Sunguni, meaning the place of white people. ${ }^{20}$ In fact, Maasai have names for most parts of the ranch - dams, pastures, and bushed areas where lions hide. These names are symbols-personal, political, and social. They reflect ecological characteristics and also tell stories of the past. Names can also reflect particular visions for the future, as illustrated by the name Maasai suggested for Manyara Ranch, Ramat. Yet in Manyara Ranch, neither Maasai historical names nor the proposed new name were accepted as official by Manyara Ranch management or the Tanzanian Land Conservation Trust donors, despite a continued promotion by AWF of Manyara Ranch as a 'Maasai' place. ${ }^{21}$

\section{Who Does Manyara Ranch Belong To?}

When I first entered the villages of Esilalei and Oltukai in early 2002, there seemed to be much confusion over Manyara Ranch, which had just become a conservation area a year prior. When I asked about the ranch, villagers often replied quickly and without pause, "it is ours [Ni kwetu]". People told me numerous times, and with a great deal of pride, how upon hearing that Manyara Ranch was going up for sale, they went to the President of Tanzania to request [kuomba] that the land be returned to them. This is because long ago the land belonged to the village of Esilalei. ${ }^{22}$ According to elders, Maasai bomas were located near the current headquarters, ${ }^{23}$ but they were abandoned in the 1930s, because of an increase in tsetse flies. Shortly thereafter, an mzungu named Farab, came to request the land from a group of elders. Farab was a herder and wanted an area to graze his cattle. Since Maasai were not currently grazing in the area requested, elders agreed to give him the land to use; they were not aware that by doing so they were giving up the land, for good. The following words from an elder born in the area, sum up this process of dispossession:

Farab came to request the land. There were only two bomas [here] then. We were going to this pori [bush/wild] area only for orpul ${ }^{4}$ [meat feasts], because of the tsetse flies. [The tsetse] had come and would hurt cattle and we had no medicine to treat them so we told them $\mathrm{OK}$, take this area and reduce the tsetse flies. We didn't write anything or get any money. [And then]... people started to increase.
.... We started to need to use this area more, but we saw that we can't go in there, because they put a border up.

The border, however, never stopped Maasai from accessing important resources inside Manyara Ranch. According to elders, throughout the various ownerships of Manyara Ranch, they maintained rights to access certain locations for water (the wells in Aladariak, in Long'abolo River), orpul gatherings, and for prayer. One of the oldest and largest Oreteti (Ficus thonningii) trees in the area is inside Manyara Ranch, and women visit these trees to pray for rain and fertility. Although it was not allowed, Maasai never stopped grazing inside the ranch, often taking livestock there at night, at the risk of being fined and beaten. As one elder responded to the question of how long he had been using the pastures in Manyara Ranch:

Since a long time ago. Since we were warriors [ilmurran.$^{25}$ We were bothered by the Wazungu, and by the government, [we were] thrown in jail, had our cattle confiscated, but we would beg to be forgiven and we would return. They don't permit us even now, but we steal [pasture].

The first mzungu owner of Manyara Ranch had difficulty managing the area and was incredibly stern with Maasai, stealing children's clothing, beating, and arresting them, if they were caught herding. The land was eventually passed on to a second owner, George Dam, also an mzungu. When George Dam and his wife were murdered (allegedly by George Dam's wife's lover), the land was taken over by the Government of Tanzania under the National Ranching Corporation (NARCO). With liberalisation in the late 1990s, as NARCO ranches across the country began to be privatised, AWF facilitated the acquisition of Manyara Ranch by the Tanzanian Land Conservation Trust, with a 99-year title deed issued on April 19, 2001. ${ }^{26}$ However, when I arrived in 2002, villagers were not aware of the lease secured by AWF. They had been assured (by their Member of Parliament and AWF) that the land had been returned to them, which explains the comments referenced above that the land belonged to them. ${ }^{27}$ Village residents (of Oltukai and Esilalei) explained how they agreed Manyara Ranch would be a conservation area, and AWF was assisting them with this by helping to manage the wildlife. Villagers did not become aware of the land sale until an ally (and former Manyara Ranch employee) translated the paperwork into Swahili and distributed the material to communities, ${ }^{28}$ at which point villagers (including steering committee members) began to demand some answers.

A meeting was held in Esilalei in 2002, where the new manager of Manyara Ranch tried to explain the whole process of the land being acquired by the Tanzanian Land Conservation Trust, why, and what it meant. He explained how the area was of global significance as a wildlife corridor and for the tourism industry in northern Tanzania. He explained that international support helped create the Tanzanian Land Conservation Trust, which was now vested with the responsibility of running the ranch for the best 
[Downloaded free from http://www.conservationandsociety.org on Tuesday, May 24, 2011, IP: 129.79.203.202] || Click here to download free Android application for journal

interest of wildlife and the two villages. The manager's words did not settle the confusion. People questioned if the agreements they made during earlier negotiations with AWF regarding grazing in Manyara Ranch were still valid. They made these negotiations thinking they had invited AWF in to help manage wildlife. Now that it was clear that AWF owned the land, ${ }^{29}$ villagers no longer understood their role in the management process. Why were villagers (or the steering committee) not involved in hiring this manager, who was standing here explaining to them the fate of Manyara Ranch? And why did they not participate in the hiring of the community liaison officer, whose job it was to coordinate communication between Manyara Ranch and surrounding villages? Matters were not helped by the fact that the steering committee itself failed to bring information back to the villages regarding their meetings in Manyara Ranch, which had already begun. Steering committee members were equally unsure of their role in the whole process, which contributed to their lack of accountability to their constituents.

\section{The Land Was Lost Again}

By 2003, when villagers were questioned openly, regarding what they thought about Manyara Ranch, nearly all of the respondents commented in one way or another that Manyara Ranch no longer belonged to them, it had been 'taken', as expressed in the following responses: ${ }^{30}$

"It is not ours. It was taken long ago, they say it is ours, but it is not, it has not yet become ours."

"I see that Manyara has been taken from us and I do not have faith that it will be ours again."

"It is just Manyara, I don't know, we hear that it is just a conservation area for wildlife."

"I see that Manyara Ranch was given out to Esilalei and Oltukai. I see that we were supposed to get grazing for cattle and wildlife, but I don't believe that this is true."

"I see that it has no purpose. They said it was ours, but now we get fined for entering and grazing on the grass."

Several people explained that there was a time when they were involved in planning how Manyara Ranch should be used, but things were not going as planned. As one villager explained, "I don't know because it is not in the plan that was laid out. They said it would be a small 'community' conservation area to help the village. If this were so, wouldn't the villagers be involved?" This sense of disappointment and confusion echoed throughout both villages, sometimes in detail and sometimes by just a dismissal of the whole situation. Such sentiments were mostly due to lack of information, but were also specifically related to prohibitions on grazing that were introduced in 2002, approved by the steering committee, but to the complete surprise and disapproval of villagers. This only proved to villagers that the land was no longer theirs, and nothing was going as initially planned and promised. This is succinctly expressed in one elder's statement:
There was a seminar regarding Manyara Ranch in 1999 in Esilalei. The government of Oltukai and Esilalei [were there] and people from AWF came. 'This land was returned to you,' AWF told us, what do you want to do with it? ... Then there was a seminar ... to plan when cattle should enter the ranch, during which months. We said that cattle should enter starting in June, through till January. But look at it today! Cattle are not allowed in at all! People are starting to complain.

The hope and pride villagers expressed about Manyara Ranch in 2002 was based on an understanding that the area had finally been returned to them, and that they had decided to make it a conservation area and grazing reserve. This was forward thinking and would bring them relief from pasture shortage, and provide financial returns from wildlife-based tourism. It would also officially return them home, in the sense of regaining legitimate control and ownership of land and resources, which they saw as part of their larger resource system, and to which memories were tied. The sense of betrayal, confusion, and resentment villagers expressed in 2003 was based on the slow realisation that the land had, once again, been taken from them. Anger and resentment continued to build as more restrictions were placed on grazing, and people were fined for 'trespassing' inside the ranch. As wildlife numbers began to increase inside Manyara Ranch, wildlife conflicts in village lands also rose (e.g., lion attacks on cattle, elephant raids of farms), ${ }^{31}$ and people began to refer to wildlife throughout the area as belonging to the Manyara Ranch manager. Resentment continued to build as participation of the steering committee in Manyara Ranch management, and involvement of villagers in any decision-making, remained minimal. Communication all around began to disintegrate.

\section{THE PARTICIPATION GAP}

Complicated politics at all levels (international, national, and local) made participation both necessary and particularly challenging in Manyara Ranch. In the Fall of 2002, the manager stated at a steering committee meeting that, "more than the trustees, is the importance of the on-site steering committee to oversee the management of the ranch". He further stated, that "no hard and fast decision will be made" by the manager, who "doesn't steer" the ranch. Yet fully engaged participation with and through the steering committee consistently failed to occur. Part of this was due to the manager's reliance on western scientific knowledge and communication techniques for conservation and livestock management. Part of it was related to complicated and highly charged politics that often lead to decisions made at the board level with the façade of participation created through the steering committee. This section explores the different ways in which participation has been constrained in Manyara Ranch, and what the implications of this participation gap are for local people and for Manyara Ranch ecology. I do not intend to suggest that local support is always needed for conservation to succeed (Brockington 
[Downloaded free from http://www.conservationandsociety.org on Tuesday, May 24, 2011, IP: 129.79.203.202] || Click here to download free Android application for journal

\section{2 / Mara J. Goldman}

2004). Indeed, wildlife numbers on Manyara Ranch have increased since its establishment as a conservation area, ${ }^{32}$ and a private tour company is now managing 35,000 acres as a high-end wildlife 'conservancy' and tourist retreat inside the ranch (http://www.manyararanch.com). However, the loss of local support and the marginalisation of local knowledge from management has begun to have consequences that threaten the image of Manyara Ranch as 'community-based', and may jeopardise future conservation goals, as discussed in the final section.

'Participation', in conservation parlance, implies that knowledge and management expertise are no longer the sole proprietary of external agencies. Rather, local people are empowered by contributing knowledge to and obtaining information from conservation projects (Chambers 1997; Barrow \& Murphee 2001). Yet, scholars have critiqued participatory processes, claiming that they are often tyrannical in merely dressing old top-down approaches in new clothing (Cooke \& Kothari 2002), reflect a modern reproduction of indirect rule (Ribot 1999), ignore complex community powerrelations, and remain externally driven (Escobar 1995; Kelsall \& Mercer 2003). Many of these critiques fit Manyara Ranch. The mandate for the creation of Manyara Ranch came from outside conservation agencies and was funded by the USAID. An expatriate man was selected by AWF as the first manager to run Manyara Ranch, and run the steering committee meetings. When the steering committee requested his resignation, the board handpicked another non-Maasai man. The steering committee was selected by Manyara Ranch management to reflect local leaders. The one village representative on the Tanzanian Land Conservation Trust Board is recognised by outsiders as a Maasai spiritual leader (an oloiboni) and often depicted in Manyara Ranch literature as a 'chief'. While he is not a chief, his wealth and spiritual power provide him with an extra degree of power within Maasai communities. The fact that he does not speak or understand English or Swahili - the two languages used at board meetings - suggests his 'participation' is merely symbolic. And finally, there is a big knowledge gap, as Maasai participants (the steering committee) never received information and training needed to participate fully in management. At the same time, Maasai knowledge, contributed through the steering committee, has never been recognised as valid for management decisions (e.g., herd management, personnel decisions, ecological planning) (Goldman 2007).

Perhaps most important, and as is often the case with 'participatory' approaches, complex local and translocal power dynamics have never been adequately addressed, including those between the Manyara Ranch Board and the steering committee, amongst members of the steering committee, between the steering committee and villagers, and among the different surrounding villages and the two partner villages. ${ }^{33}$ The Chairman of the Board is recognised as an important spokesman for Maasai (in this district and across Tanzania); ${ }^{34}$ he is also politically and socially affiliated with neighbouring communities ('peripheral villages' to Manyara Ranch), which are of a different, though related ethnic group, with historically antagonistic relations with Maasai when it comes to land. These relations and the inclusion of peripheral villages in Manyara Ranch management and use rights (they have their own liaison officer, see below on grazing), added a layer of political complexity to the mix; additionally, how the steering committee was selected, and what its role was, was never adequately communicated to villagers. All this created a crisis of legitimacy that continues to this day.

Nonetheless, steering committee members, at least in the beginning, tried to 'participate' in Manyara Ranch management, but found it difficult to do so. The meetings were led by the manager in a Western style format, which left little space for Maasai to contribute without violating their own social norms and practices (Goldman 2007). Decisions were often made ahead of time and brought to the committee for approval. Perhaps for this reason, combined with the power wielded by the Chairman of the Board, members of the steering committee did not see themselves as being anything more than puppets - pulled by the more powerful voices of politicians and conservationists on the board. This alone often left many unwilling to participate. ${ }^{35}$ It also enabled the eventual co-optation of the steering committee by the Chairman of the Board, ${ }^{36}$ as well as the inability of the steering committee to enforce policies in their villages. Eventually a consultant was hired to address the role of the steering committee. He determined that the steering committee was more of an advisory committee, and a suggestion was made to change the name. In the summary report of the training seminar he held, the list of steering committee responsibilities included: "to advise the Tanzanian Land Conservation Trust Manyara Ranch Management without interfering with their given responsibilities".

\section{Manyara Ranch Grazing Policy}

The introduction of a new grazing policy in Manyara Ranch in 2003 was particularly contentious and reflects the lack of agency steering committee members had during management negotiations. According to the manager, it was necessary to institute a grazing plan to avoid a 'free for all' situation where herders would ruin (i.e., overgraze) ranch pastures. He drafted a plan and called a meeting to discuss it with the steering committee. While the manager was interested in their input, ${ }^{37}$ steering committee members did not feel free to contribute to the discussion and rather felt they had no choice but to agree with the plan. After the meeting, many of the steering committee members acknowledged that they did not agree with the plan and wished to discuss alternate proposals, but found it difficult to do so. As one member stated:

We talked about this before at a big meeting. When we should use the Ranch... So we suggested starting [grazing] in May... So now the decision came to be switched. And this business of numbers of cattle [e.g., a grazing quota] has brought a lot of problems with villagers and with us 
[Downloaded free from http://www.conservationandsociety.org on Tuesday, May 24, 2011, IP: 129.79.203.202] || Click here to download free Android application for journal

[the steering committee], we are not happy. But the first schedule was good. But [this one] we did not agree well, we did not understand fully in that meeting.

The policy proposed by the manager allowed villagers to make individual requests to graze their cattle in Manyara Ranch pastures during the dry season, but only after it was shown that no grass remained within a certain radius of the individual's home boma. Access was granted only to a portion of the milking herd, pictures of cattle were taken, and names of herd boys obtained. ${ }^{38}$ The plan was designed to limit access to Manyara Ranch pastures by village cattle, except in severe need. Today, requests are no longer made by individual herders, but by the village government to open Manyara Ranch pastures to village cattle in the dry season, once village pastures have been depleted. Yet, the second Manyara Ranch manager tried to discourage any grazing on Manyara Ranch pasture, promoting instead zero grazing at home, ${ }^{39}$ and the planting of grass in village land. Much of the anger by villagers regarding Manyara Ranch has been related to cattle being caught and herders fined for using Manyara Ranch pastures without explicit permission. This new 'community-based' conservation trust seemed to be running on a fines-based approach.

Villagers never did fully accept the original grazing plan, nor did the steering committee. Steering committee members complained, fought, and 'stole' grass when and how they could. The first manager (who put the plan in place) complained that steering committee members agreed to restrictions and then systematically broke the rules. He viewed such actions as an abuse of the steering committee power and an inability to follow rules. He did not see it as a way for steering committee members to assert power in an otherwise powerless relationship. Steering committee members did not feel they had the power to disagree with the plan, but they did have the power to break the rules as they saw fit, setting the stage for others to also break the rules.

The steering committee did not, however, just sit back and break the rules; there was a genuine desire by many to play a more active role in Manyara Ranch management, but they were just not sure how to do so. As early as 2002, the steering committee Chairman requested legal assistance and training for the steering committee. He agreed that cattle should only enter Manyara Ranch 'by law', because, he explained, Manyara Ranch was "our place, to guard and to protect". It was their duty, he said, "kulinda alalili yetu" (to protect our reserve pastures, see below on alalili). But, he explained, things were not going as planned. The plan for cattle to access Manyara Ranch pasture in the dry season was meant only for the villagers of Oltukai and Esilalei, 'not for everyone'. "But it didn't work", he lamented, "People enter Manyara". A concept plan produced by AWF in 2000, recognised the unanimous agreement among steering committee members and village leaders that other pastoral communities should not have access to Manyara Ranch, with neighbouring villages allowed access to one of Manyara Ranch dams 'for livestock watering only' (African Wildlife Foundation 2000: 44).
The request by the partner village governments (Oltukai and Esilalei) to limit grazing in Manyara Ranch to herders from only their villages was a strategic request, but also a difficult and political one to grant. Politics made it difficult for Manyara Ranch management to withhold grazing access to herders in neighbouring ('peripheral') villages, yet denying this request had its consequences. It made it more difficult for the steering committee to agree to grazing restrictions imposed on them, led to the plan 'not working' as expressed by the steering committee Chairman above, contributed to a loss of faith by residents in the partner villages that Manyara Ranch was theirs, and made it difficult to manage grazing in Manyara Ranch according to Maasai custom as now others were being granted permission by Manyara Ranch management on a different system.

\section{Maasai Pasture Management: Grazing, Burning, Livestock, and Wildlife}

Maasai manage pastures through regulated grazing, controlled burning, grazing reserves, and seasonal mobility. Historically, Maasai were more mobile with their herds, and pasture resources were negotiated through social networks (age-set affiliations, kinship ties, marriage) and residence patterns (Western \& Dunne 1979; Worden 2007). Elders regulated access to communal pastures and water sources. There were grazing areas set aside as 'drought reserves', conserved for use only in exceptionally dry years, and alalili (also called olapololi) reserves set aside for grazing by sick cattle and calves. Infringements against established protocols regulating pasture or water were met with fines and punishments (Homewood et al. 2004).

Today, mobility patterns have been greatly reduced as a result of the loss of pasture to conservation areas and farms and increased sedentarisation by Maasai into villages. Yet many Maasai continue to access pasture through social networks and kinship ties across village lines. Most drought reserves have been lost to conservation areas, but alalili pastures remain scattered across village space. Alalili pastures can be set aside by an individual boma, by a grouping of bomas, or by an entire sub-village. Use of alalili pasture is strictly monitored by the elders, who continue to play a role in regulating access to water and pastures inside village boundaries. Village governments often designate areas where bomas and farms are permitted and areas for grazing in different seasons.

Residents in Oltukai and Esilalei had plans for how and when they would use pastures in Manyara Ranch and were ready to regulate this use, when they thought the area was being returned to them. They planned to use Manyara Ranch for grazing during the dry season, and during a season called orkisirata (the early rains), when herders often migrate with their cattle to access fresh grass and water. Manyara Ranch usually receives rainfall early in orkisirata and has dams that stay full until the heavy rains. Access to Manyara Ranch during these seasons was to be regulated by the elders, so as to not jeopardise the conservation potential of the area. For, while most villagers 
[Downloaded free from http://www.conservationandsociety.org on Tuesday, May 24, 2011, IP: 129.79.203.202] || Click here to download free Android application for journal

wanted access to Manyara Ranch for grazing (and some for farming), most were also interested in maintaining wildlife in the area. When asked how they would run Manyara Ranch if they were in charge, many village residents argued that while they would like the ranch to be theirs, they wanted it managed as a conservation area and pasture reserve, as reflected in the following statements:

I would like it to be ours completely, like long ago. My advice would be to leave it as it is, a small conservation area, with the cattle of the ranch there, and our cattle there, all mixed together. We would all mix together and not kill any animals (village elder, Esilalei).

We would run the area like it is ours, not to mess [it] up. Not like you can just enter because there is grass. We are not worried about this. ... we decided we want this area to be a conservation area, [it is] not another group that came and told us. The elders can place a law that says people cannot just enter the area freely. (steering committee member)

The majority of responses to this question suggested a desire to keep Manyara Ranch as a place of wildlife and cattle, used for grazing only in the dry season and when needed during the short rains (orkisirata). $81 \%$ of respondents $(38, n=43)$ stated that the area should support wildlife populations. However, for Maasai, supporting wildlife does not necessarily mean restricting livestock grazing, or even human residence and farming. In fact, $42 \%$ of respondents suggested that permanent bomas should be allowed in the ranch, and others (34\%) suggested farming be allowed. ${ }^{40}$ Yet most respondents did not see this as antithetical to conservation, with many commenting that wildlife should stay, just as they are now in the village (with bomas and farms). Additionally, several of the respondents who mentioned that farms and/or bomas should be allowed in Manyara Ranch, spoke about spatial or temporal planning of Manyara Ranch pastures together with village pastures. For instance one respondent suggested that,

We should benefit from dry season pastures [in Manyara Ranch] and move temporary bomas there, because wildebeest are not able to give birth inside [the ranch] because there is so much grass. When the wildebeest birth at the lake [inside the village], cattle should be able to go into the ranch and then they will not die [from Malignant Catarrhal Fever, a disease transferred from calving wildebeest to cattle].

This statement illustrates a clear understanding of both wildlife and livestock needs in thinking about how to manage Manyara Ranch as part of a larger grazing system together with village lands. There were also some very clear ideas expressed as to exactly how grazing, both inside and outside the ranch, could be managed, with reference to seasonal use of pastures, letting pastures rest, and taking advantage of different pasture types across the entire area. As one elder explained:
I can see an area where cattle can enter to eat grass in the wet season [inside Oltukai] and another area in the dry season [inside Manyara Ranch]. ... We [the elders] can do it better then the government can. We can set up such a grazing arrangement in the village of wet and dry season grazing areas. If a person passes through [in the wrong season], fine them a bull!

In addition to planning seasonal management of grazing access, many villagers suggested that Manyara Ranch be treated as an alalili. Alalili pastures are perhaps the most seriously enforced grazing management schemes Maasai have. If anyone is caught inside an alalili without permission, and with healthy full-grown cattle, they are fined heavily (and if young, beaten). Even if all the grass in the surrounding area is finished, an alalili is not touched until it is officially opened, and then only for cattle in need.

Another important component of Maasai range management has historically been the use of controlled burning of pastures. As one elder explained, "after 2 years of no burning, the grass becomes like trees, it is no good, it is not eaten by cattle. Long ago, every 2 years we would burn. Then we would get good grass". Grass that is not grazed and not burned is also not eaten by many wildlife species, particularly wildebeest. Today, burning is illegal and is currently prohibited in Manyara Ranch. The first manager was not opposed to fire per se, but established a no-burn policy until the ecology of the ranch was well understood (Goldman 2007).

Fires still occur in village and Manyara Ranch land, and because no one claims ownership, they often burn out of control. One of the most valuable grazing areas for wildlife in Manyara Ranch in 2005 was an area that was burned 'accidentally' two years earlier. Another place within Manyara Ranch favoured by plains animals (zebra and wildebeest) was the short grass plains adjacent to village land, where illegal grazing of village cattle occurred. There are some grasses that, in certain circumstances, respond positively to being grazed by producing new, fresh growth (compensatory grazing, see McNaughton \& Banyikwa 1995; McNaughton 1979). Fire can produce similar results. As a Maasai elder explained:

If there are two places with these grasses (Sporobolus sp.), one has been grazed and the other not, the place that has not been grazed will become bush. The one that was grazed by cattle will be better. It is the same with fire. A place that has been burned will be better than a place that has not been burned... So for instance, with alalili, every 2 years we burn it so that it gets healthy, so that good, healthy grass grows back.

When talking about the history of Manyara Ranch, people spoke positively about the use of fire to manage pastures. A group of elder women stated, that in the past, "no one hated [fire] ... We burned Manyara Ranch to get fresh grass and to kill ticks and tsetse". ${ }^{41}$ People also spoke in great detail about 
[Downloaded free from http://www.conservationandsociety.org on Tuesday, May 24, 2011, IP: 129.79.203.202] || Click here to download free Android application fo journal

the burning system used by the second owner of Manyara Ranch in comparison to the current no-burn policy:

When George Dam came he put fire breaks and would burn one side one year another side another year... it was good. Today it has become pori [bush]; it is full of endudulen bush [Dichrostachys cinerea] because of no burning. ... If we burn [the endudulen] would be finished but without fire it will just increase. Now this area in Manyara Ranch has no good grass, you can't even pass with a car. If you burn, the grass will return, it will be joy [raha] for the wildlife ... Cattle, even people have no place to pass. Today it has become useless bush [pori, haini maana]. Even if wazungu come to take pictures they cannot see, they can't even pass. Without burning, there is nothing. If you burn it will be a good conservation area.

Burning is clearly a controversial issue, and one that needs to be well managed. Yet Maasai knowledge and management techniques (including burning) are not taken into consideration by Manyara Ranch management, despite one of the stated goals of Manyara Ranch being to support 'traditional pastoralism'.

\section{THE CONSEQUENCES FOR CONSERVATION AND PEOPLE}

With the lack of Maasai participation in managing Manyara Ranch, there has been no inclusion of Maasai range management techniques, including fire, regulated grazing, and the protection of alalili pastures. Rather than plan grazing for the entire area in a sustainable manner, herders manage pastures in their own villages, set aside alalili pastures near bomas and in sub-villages, and wait for Manyara Ranch to be opened for grazing. Many illegally enter Manyara Ranch throughout the year, even when it is not open, at the risk of being caught and fined. And others still set fire illegally to pasture on the edge of Manyara Ranch, knowing it will get swept into the ranch and perhaps lead to improved pastures once the rains come. Manyara Ranch has become another grazing area removed from Maasai control, but still perceived of as a part of Maasai grazing system, and thus still used, if not properly managed or protected, by Maasai. This could impact how conservation in Manyara Ranch succeeds, how pastures are cared for, and how other conservation-related interventions are viewed.

\section{Pasture Protection}

The prolonged drought of 2009 brought Maasai in large numbers, with their cattle, from as far away as Kenya into Oltukai and Esilalei villages in search of water and pasture. Part of what drew them to the area was awareness of pasture and water inside Manyara Ranch, with little knowledge regarding rules of access. Following Maasai custom, fellow Maasai could not turn needy herdsmen away, so the migrants were allowed to set up camp in village land from where they illegally entered Manyara Ranch. Manyara Ranch received the help of government officials and local tour companies to police the area and arrest, fine, and evict migrant herders who entered the ranch illegally. Members of the steering committee acted as mediators, trying to keep herders out of Manyara Ranch while working with Manyara Ranch management to minimise the punishments (fines, imprisonment, confiscation of cattle). They only partly succeeded with both objectives. Herders promised not to graze in Manyara Ranch, only to return the next day; Manyara Ranch management eventually called in the special (armed) police force to remove people by force. Manyara Ranch management punished local Maasai by denying them access to pastures until they evicted all the visiting herders. Asking needy herders to leave would have been a violation of Maasai custom, and villagers refused to comply. ${ }^{42}$ Instead, local Maasai entered Manyara Ranch illegally, together with the migrant herders, making any sort of enforcement even more difficult.

In discussing their own illegal use of Manyara Ranch at the start of the drought, a village elder said, with a laugh, "you know there is no purpose/significance [haina maana] in Manyara Ranch right now. No purpose at all". During a drought, rules and restrictions are negotiated or ignored, as people are in desperate need for pasture and water. But that is not what the elder was speaking of. He was suggesting that Manyara Ranch was no longer respected by anyone. It had become the very 'free for all' that the first manager was so afraid it would, if grazing was not strictly controlled. Yet during the drought, pasture areas in both villages of Oltukai and Esilalei that were set aside as alalili, remained intact. All alalili pastures - individual ones and those set aside by sub-villages - were successfully protected from grazing from both resident and migrant herders, even when all surrounding pastures were depleted. Perhaps if villagers had succeeded at managing Manyara Ranch as their alalili, it too would have received the same degree of respect and protection during the drought.

\section{Wildlife Conservation}

When the village leader (mentioned above) said that Manyara Ranch had lost its purpose, he was not only referring to illegal grazing, but also to Manyara Ranch as a protected space, as a conservation area. The year prior, he used nearly the same words to talk about lion hunting in Manyara Ranch. "Lion hunting is allowed inside a conservation area now", he told me shaking his head. "What kind of conservation area is that?" He questioned. He was referring to a settlement that Manyara Ranch management had made, allowing ilmurran ${ }^{43}$ to hunt lions that had killed cattle, as long as they phoned Manyara Ranch game scouts first to inform them of the hunt. The assumed logic was that the phone call would enable the game scouts to intervene and prevent the kill, but this was not happening and more and more lions were being killed by angry ilmurran.

The ilmurran were angry not because lions were killing 
[Downloaded free from http://www.conservationandsociety.org on Tuesday, May 24, 2011, IP: 129.79.203.202] || Click here to download free Android application for journal

\section{6 / Mara J. Goldman}

cattle; this was normal. They were angry because of what they perceived as a lack of respect by Manyara Ranch management for their culture of lion hunting (see Goldman et al. 2010). A particularly heated exchange between a group of ilmurran from both villages and Manyara Ranch management occurred where celebrating ilmurran were forced to give back the trophy pieces they usually took from a lion kill (the tail, paw and claws), and were stopped from continuing their celebratory [olamaiyo] dance. Ilmurran complained that the hunt had been 'halali' (a legitimate hunt), because a cow had been killed, and such hunts are legal in Tanzania. In response to this event, ilmurran began pursuing lion hunts whenever possible. They were angry and explained that they should not be expected to behave according to the rules and reconcile things with the ranch, because they had been mistreated, belittled " $[K w a$ sababu tumeonewa]". "Why should we respect the rules of Manyara Ranch", they asked, "when Manyara Ranch does not respect us?" An elder confirmed the situation stating, "we have no reason to follow the rules. We no longer have any faith/trust [imani] in Manyara Ranch".

This lack of faith regarding Manyara Ranch meant community members were less likely to work towards other conservation-related goals with Manyara Ranch management or AWF. In fact, most villagers were unable to differentiate between Manyara Ranch, AWF, and the Tanzanian Land Conservation Trust. When one of the partner villages was approached by AWF to participate in a new conservation project to protect wildlife corridors on village lands, they refused (Goldman 2009). Villagers stated that it was not a good idea to start a new project with an organisation with which they already had bad relations. This is not to say that relations were not good with some people, and did not wax and wane as relations with any outside organisation do. Yet the personal history that people had with Manyara Ranch, and the hope and excitement they had when they thought that it had been returned to them, meant that all the conflicts and disappointments that followed were particularly damning, if not necessarily unique.

\section{CONCLUSION}

"I do not hate wildlife and not want them here. Nor do I like them for tourists because we don't see them [tourists]. Wildlife on the side of tourists are not the problem. It is the people who protect the wildlife that are the problem."

— Maasai elder, Oltukai village, Tanzania 2009

The above quotation comes from a Maasai elder from Oltukai village, one of the partner villages of Manyara Ranch. He was referring to AWF, the organisation responsible for creating Manyara Ranch, and for the creation of another new conservation area in a neighbouring village, which had resulted in the loss of additional grazing land (Igoe \& Croucher 2007). It is not, therefore, the existence of wildlife in the area that is resented, it is the actions of conservation organisations- actions that seem to always lead to the loss of control of and access to important grazing pastures for Maasai, and the alienation of land. The elder who made this statement was on the trip to Ngorongoro, about which this paper began. He had been there before, and acted as the excited tour guide showing Neserian wildlife inside the crater. He took pictures of lions and watched rhinos with awe. And he told me the story (once again) of why it is that Maasai in Ngorongoro Conservation Area have no rights to farm, but he and his neighbours do. Yet his farm borders Manyara Ranch, and he has been asked to move it. And he was recently fined and threatened by the police for grazing his own cattle inside Manyara Ranch, and for providing shelter to migrating Maasai and their cattle.

The question regarding human rights and conservation is therefore not only about forced evictions, although these represent a violent (and important) extreme. ${ }^{44}$ Even those who are not evicted from their homes often lose access to important places, and more often still, lose control over how land and resources are managed in places considered part of their resource base. Manyara Ranch has brought benefits to the 'partner villages' through employment as game scouts and herders, through breeding opportunities with Manyara Ranch improved livestock breeds (sheep and cattle), and through access to dry season grazing. Yet in many ways these are all consolation prizes. In fact, villagers complained to their Member of Parliament, that such 'jobs' did not mean ownership and control of Manyara Ranch, which is what they had been promised. ${ }^{45}$ Today villagers are complaining about an agreement between the Tanzanian Land Conservation Trust and a new tour company to control over 35,000 acres of land inside the ranch. Sceptical they will receive any benefits from tourism, villagers are concerned about increased restrictions on grazing rights, and see this as final confirmation that Manyara Ranch has been 'lost' ${ }^{46}$ Yet many see no outlet for their complaints: Manyara Ranch workers fear dismissal, and many villagers are unaware of where to go. ${ }^{47}$

If they owned/controlled Manyara Ranch, community members would have access to more grazing, and they would control the breeding, care, and sale of Manyara Ranch cattle. But what about conservation? As shown above, there was general agreement among residents in the 'partner' villages that Manyara Ranch should be run as a pasture area for wildlife and livestock, that it should be a conservation area. In fact, Maasai were in favour of eliminating Manyara Ranch cattle, except for a small herd for breeding. This would have reduced grazing pressure, leading to more pasture for wildlife and Maasai cattle. This request was not granted; in terms of conservation outcomes, Maasai were never given the opportunity to try that either. This is perhaps the biggest reason that Manyara Ranch is a conservation opportunity lost - for Maasai and for those interested in seeing what community-based conservation from the ground up might look like, if people were given the opportunity to try.

Moreover, the model on which Manyara Ranch is based, the land trust, and the Tanzanian Land Conservation Trust itself, is being promoted internationally as a conservation success, and 
[Downloaded free from http://www.conservationandsociety.org on Tuesday, May 24, 2011, IP: 129.79.203.202] || Click here to download free Android application for journal

Strangers in their own land / 77

being replicated elsewhere (see http:/www.awf.org/content/ solution/detail/3376 on the Kenyan Land Conservation Trust). In this paper, I have shown that the rhetoric of 'community' respect promoted by the Tanzanian Land Conservation Trust does not match the pattern of community exclusion that has occurred in Manyara Ranch. I have also shown that this pattern of excluding local people from management decision-making, and disrespecting their rights to and their memories associated with Manyara Ranch is leading to outcomes that could be detrimental to the very conservation success of the area. In other words, a participation gap is not only an infringement on human rights, but can pose threats to conservation success.

\section{ACKNOWLEDGEMENTS}

Funding for this research was provided by a National Science Foundation International Research Fellowship Postdoctoral Grant (\#0602034). Findings also draw from research funded by a FulbrightHays Dissertation Research Fellowship, and a National Science Foundation Dissertation Improvement Grant. I am grateful to the Tanzanian Commission for Science and Technology for supporting this research, and to Manyara Ranch management (from 2002-2005) and the Tanzanian Land Conservation Trust steering committee for welcoming my presence at their meetings and facilitating my research. I also thank residents of Oltukai and Esilalei villages for their support and hospitality. This paper was improved by comments from Nicole Smith, Alicia Davis, Alais Morindat, and an anonymous reviewer. Responsibility, however, lies solely with the author.

\section{Notes}

1. Maasai are one of the most recognisable ethnic groups in Tanzania (and Kenya), their pictures frequently on the covers of tourist and conservation brochures. Recognised as pastoralists, most Maasai also practice agriculture and participate in several other income earning activities.

2. Boma is Swahili (bomas=commonly used Anglicised plural). The Maasai word is engang. The English translation is village or homestead. A boma is a settlement of houses most commonly comprising the polygamous families of men (relatives or friends) or one single polygamous family, around a single cattle enclosure usually encircled by a thorn fence.

3. This story was told to me, by different Maasai at different points in time, throughout fieldwork.

4. Ngorongoro Maasai are also officially 'Kisongo'. However, within the larger section of Kisongo Maasai, smaller breakdowns are recognised, and here Kisongo refers to those in the area of Kisongo proper, near Monduli. These different groups are sometimes referred to as inkutot, with the larger sections referred to iloshon. (Goldman 2006).

5. Maasai residents of Ngorongoro Conservation Area are prohibited from burning, farming, building 'modern houses', and grazing cattle in the crater. In this way and others, it is becoming extremely difficult for Maasai to actually live and survive in Ngorongoro Conservation Area (McCabe 2002).

6. This is specifically the case in Ngorongoro. In other places, Maasai have benefit financially from conservation-related tourism, but usually through activities they initiated themselves with private ventures (Nelson et al. 2009; Sachedina 2008).

7. Drawing from the model used by Nature Conservancy as a way of acquiring and managing land for conservation (Sumba et al. 2005).

8. Tsetse flies are vectors for the disease trypanosomiasis which affects cattle, sheep, goats, camels and many game animals, and also sleeping sickness in humans.
9. There is a great deal of literature on this and often with a detailed historicising of local land use as well as memories of the areas in question. For east Africa, see in particular Neumann (1998), Brockington (2002), and Shetler (2007).

10. I do not mean to imply that communities are homogenous units. Community representation, benefits, and risks are often unevenly distributed along lines of gender, age, wealth and ethnicity. Yet community units are often drawn, sometimes to match administrative units (i.e., villages), or customary units of management, for conservation purposes. See Agrawal \& Gibson (2001).

11. I utilise 'local' for lack of a better term to refer to the knowledge (ecological, political, social, cultural) of people living in or adjacent to a conservation area. Elsewhere I acknowledge the need to be cautious about drawing too strong a distinction between scientific and 'other' (e.g., local) knowledge productions (Goldman 2007).

12. Brockington et al. (2006) rightly argue for more research on the different ways that people can and do co-exist with nature. Research on this is being conducted in the Maasai Mara region in Kenya (where human poverty, biodiversity concerns, and tourism interact in often challenging ways), see Reid et al. (2003).

13. One could refer to this as the foot dragging and other 'weapons of the weak' (Scott 1987).

14. In the beginning, there was no real difference between the Tanzanian Land Conservation Trust and AWF. For legal and accountability issues there was then a great deal of effort put into distinguishing the two as different entities. However, there was recently a proposal put forth to the board to allow for the direct overlap between the two organisations, in a legal manner.

15. He resigned from his position as Prime Minister following a scandal in which he was implicated.

16. The chairmen from both villages are on the steering committee and are invited to board meetings, but they do not have voting power at these meetings.

17. See Sumba et al. (2005); Henson et al. (2009); http://www.awf.org/ content/solution/detail/3505. Accessed on January 6, 2010; and http:// www.nature.org/wherewework/northamerica/states/colorado/features/ art28913.html. Accessed on January 6, 2010.

18. It can be argued that there is nothing 'new' about this, as Maasai had been using the area for grazing, together with ranch cattle and wildlife for years. It is 'new' in being an official mixed-use conservation area.

19. This information came from a conversation with the manager at the time.

20. A Maasai pronunciation of the Swahili word Uzunguni. Mzungu (sg., wazungu, pl.) is used to refer to white people in general. Placing a ' $\mathrm{u}$ ' pre-fix and 'ni' suffix, creates a word that means the place of foreigners/ white people. It is quite telling that Maasai use this word to refer to the area occupied by the management of the ranch.

21. See Sachedina 2008 for a discussion of the power of donors and the role of marketing in Manyara Ranch as an AWF flagship conservation enterprise.

22. The village of Esilalei was divided into the two villages of Oltukai and Esilalei in 1999, at the villagers' request. The elders who gave the land away did so before villages were officially established by the Tanzanian state, but were among the original inhabitants of what became Esilalei village.

23. From a group interview with women from Oltukai and Esilalei on the history of the area (including Manyara Ranch) October 7, 2003, and an interview with a male elder from Esilalei.

24. Orpul gatherings comprise a group of ilmurran (young men, 'warriors', see Note 25) and some elders (historically women were involved as well) that go to stay in the 'bush' for 1-3 weeks to eat meat and drink medicinal soups to gain strength for the dry season ahead. These gatherings are important cultural practices, where knowledge is exchanged between older and younger age-sets, stories told, and age-set bonds strengthened.

25. Maasai men have their lives organised according to age-grades. The 
Ilmurran age-grade refers to the period of time from when men are circumcised (during the teens) till they graduate to elderhood as an entire group (age-set). Ilmurran are often referred to in English as 'warriors', as they are recognised as the soldiers of the society.

26. The price that was paid is rumoured to be steep. The land and assets were said to be worth USD 233,000 (Sumba et al. 2005). According to Sachedina (2008: 347), AWF invested approximately USD 2.5 million directly into Manyara Ranch, in the first six years.

27. Several people told me of stories of a meeting where the Member of Parliament held up a piece of paper and declared that this was proof that the area had been returned to them. Nobody actually saw the piece of paper he was holding.

28. This man was subsequently fired from his job at Manyara Ranch.

29. While ownership was officially vested in the Tanzanian Land Conservation Trust, villagers did not recognise a difference between the Tanzanian Land Conservation Trust and AWF, for good reason. Manyara Ranch was facilitated (and still is) through the AWF office in Arusha town, and the cars for Manyara Ranch carry the AWF name.

30. From interviews conducted in $2003(n=43)$, translated from Maa (the Maasai Language) and Swahili by two assistants and the author.

31. This statement is based on multiple and continual complaints made by villagers over this time period (during which I was living in Oltukai village). People spoke with anger about the rise of elephant and lion numbers in Manyara Ranch and what this meant for their crops and livestock.

32. This comment is based on local knowledge from villages, and statements made by wildlife researchers. The lack of baseline wildlife data makes it difficult to draw direct conclusions from recent wildlife census regarding population trends since it became a conservation area.

33. When one of the villages involved questioned the make-up of the steering committee and tried to change it, through village-wide meetings with full participation, they were challenged by Manyara Ranch management and people were accused of playing politics.

34. He was recently chosen as 'Chairman' of all Maasai customary leaders (ilaigwenak) for Tanzania. While this position is contested by many, it reflects the complex politics involved.

35. Members of the steering committee expressed this during a group interview in 2003 .

36. In January 2004, the steering committee drafted a letter to the Chairman of the Board requesting the removal of the current manager whom they claimed did not respect them. It is rumoured that the Chairman of the Board facilitated this move himself, and many steering committee members now regret this action.

37. After this particular meeting, the manager expressed his frustration with me that steering committee members contributed little to the discussion.

38. This description is based on the situation at the end of 2003; there was a change made later regarding the number of cattle, where the initial limit of 50 heads of cattle to each request was eliminated.

39. This refers to keeping cattle stationary and bringing grass to them. The system is being used now with some Manyara Ranch cattle and a seminar was held by Manyara Ranch to teach villagers how to feed cattle in this manner.

40. However, today most agree that there is no need to put temporary bomas inside Manyara Ranch.

41. From a group interview with women from Oltukai and Esilalei on the history of the area (including Manyara Ranch) on October 7, 2003.

42. Interestingly, however, many individuals in both villages confided in me that they were happy that Manyara Ranch was trying to remove the visiting herders. They too did not want the migrants there as resources were limited, but they did not have the ability to refuse them access.

43. See Note 25 on ilmurran. They are ones usually responsible for hunting lions within Maasai communities.

44. Evictions in the name of conservation need to be interrogated as well, as they continue to happen in Tanzania, as witnessed by the recent evictions in Loliondo Division of Ngorongoro District, to make way for a game reserve for wildlife hunting. For more information see Nelson 2010.

45. This complaint was made in a meeting that the Member of Parliament called in 2002 to address unrest regarding Manyara Ranch. I was not present but was told about the meeting by those who had attended.

46. Additionally, there are complaints about how much money has been obtained by Manyara Ranch in the name of 'community support', with little or none of this money making its way to the communities. One example that was disclosed to me included funding for an ambulance to help villagers, which never materialised. Currently, villagers can receive assistance from Manyara Ranch vehicles to carry the sick if they pay for fuel.

47. An official complaint was filed by Oltukai village to the USAID against Manyara Ranch over a series of trenches that were built in village land (as a water catchment/pasture development project). With an American tour operator working in the village leading the complaint, the USAID came out to investigate. However, the issue was never rectified and today the trenches remain in place, leading one resident (on whose land the trenches were dug) to open a personal lawsuit against AWF.

\section{REFERENCES}

Adams, W.M., R. Aveling, D. Brockington, B. Dickson, J. Elliott, J. Hutton, D. Roe, B. Vira and W. Wolmer. 2004. Biodiversity conservation and the eradication of poverty. Science 306(5699): 1146-1149.

African Wildlife Foundation. 2000. Manyara trust lands: Management zone concept plan. Arusha, Tanzania: African Wildlife Foundation.

African Wildlife Foundation. 2005. African heartland news. A Newsletter for Partners of the African Wildlife Foundation. Washington, DC: African Wildlife Foundation.

Agrawal, A. and C.C. Gibson. 2001. Communities and the environment: Ethnicity, gender, and the state in community-based conservation. New Brunswick, NJ: Rutgers University Press.

Agrawal, A. and K. Redford. 2006. Poverty, development, and biodiversity conservation: Shooting in the dark. Wildlife Conservation Society Working Paper 26: 305-308.

Agrawal, A. and K. Redford. 2009. Conservation and displacement: An overview. Conservation and Society 7: 1-10.

Barrow, E. and M. Murphee. 2001. Community conservation: From concept to practice. In: African wildlife \& livelihoods (eds. Hulme, D. and M. Murphee). Pp 24-37. Portsmouth, NH: Heinemann.

Brockington, D. 2002. Fortress conservation: The preservation of the Mkomazi Game Reserve, Tanzania. Bloomington, IN Indiana University Press.

Brockington, D. 2004. Community conservation, inequality and injustice: Myths of power in protected area management. Conservation and Society 2(2): 411-432.

Brockington, D. and J. Igoe. 2006. Eviction for conservation: A global overview. Conservation and Society 4(3): 424-470.

Brockington, D. and K. Schmidt-Soltau. 2004. The social and environmental impacts of wilderness and development. Oryx 38(2): 140-142.

Brockington, D., J. Igoe and K. Schmidt-Soltau. 2006. Conservation, human rights, and poverty reduction. Conservation Biology 20(1): 250-252.

Chambers, R. 1997. Whose reality counts? Putting the first last. London: Intermediate Technology Productions.

Cooke, B. and U. Kothari. 2002. Participation: The new tyranny? New York, NY: Zed Books.

Escobar, A. 1995. Encountering development. Princeton, NJ: Princeton University Press.

Gardner, B.R. 2007. Producing pastoral power: Territory, identity and rule in Tanzanian Maasailand. Ph.D. Thesis. University of California, Berkeley. Berkeley, USA.

Gadgil, M.,F. Berkes and C. Folke. 1993. Indigenous knowledge for biodiversity conservation. Ambio 22: 151-156. 
[Downloaded free from http://www.conservationandsociety.org on Tuesday, May 24, 2011, IP: 129.79.203.202] || Click here to download free Android application for journal

Goldman, M. 2003. Partitioned nature, privileged knowledge: Community based conservation in Tanzania. Development and Change 34(5): $833-862$.

Goldman, M.J. 2006. Sharing pastures, building dialogues: Maasai and wildife conservation in Northern Tanzania. Ph.D. Thesis. University of Wisconsin-Madison, Madison, USA.

Goldman, M. 2007. Tracking wildebeest, locating knowledge: Maasai and conservation biology understandings of wildebeest behavior in Northern Tanzania. Environment and Planning D: Society and Space 25: 307-331.

Goldman, M. 2009. Constructing connectivity? Conservation corridors and conservation politics in east African rangelands. Annals of the Association of American Geographers 99(2): 335-359.

Goldman, M., J. Roque de Pinho and J. Perry. 2010. Maintaining complex relations with large cats: Maasai and lions in Kenya and Tanzania. Human Dimensions of Wildlife 15(5): 332-246.

Henson, A., D. Williams, J. Dupain, H. Gichohi and P. Muruthi. 2009. The heartland conservation process: Enhancing biodiversity conservation and livelihoods through landscape-scale conservation planning in Africa. Oryx 43(04): 508-519.

Homewood, K., E. Coast and M. Thompson. 2004. In-migrants and exclusion in east African rangelands: Access, tenure and conflict. Africa 74(4): $567-610$.

Hughes, L. 2006. Moving the Maasai: A colonial misadventure. New York, NY: Palgrave Macmillan Press.

Hulme, D. and M. Murphee. (eds.). 2001. African wildlife \& livelihoods: The promise and performance of community conservation. Portsmouth, NH: Heinemann.

Igoe, J. 2002. National parks and human ecosystems: The challenge to community conservation. In: Conservation and mobile indigenous peoples: Displacement, forced settlement and conservation (eds. Chatty, D. and M. Colchester). Pp. 77-96. Oxford: Berghan Books.

Igoe, J. 2004. Conservation and globalization: A study of national parks and indigenous communities from East Africa to South Dakota. Belmont, CA: Wadsworth/Thompson Learning.

Igoe, J. 2007. Human rights, conservation and the privatization of sovereignty in Africa. Policy Matters 14: 241-251.

Igoe, J. and B. Croucher. 2007. Conservation, commerce, and communities: The story of community-based wildlife management areas in Tanzania's northern tourist circuit. Conservation and Society 5(4): 432-449.

Kelsall, T. and C. Mercer. 2003. Empowering people? World vision \& 'transformatory development' in Tanzania. Review of African Political Economy 96: 293-304.

McCabe, J.T. 2002. Giving conservation a human face? Lessons from forty years of combining conservation and development in the Ngorongoro Conservation Area, Tanzania. In: Conservation and mobile indigenous peoples: Displacement, forced settlement, and sustainable development (eds. Chatty, D. and M. Colchester). Pp. 61-76. Oxford: Berghahn Books.

McNaughton, S.J. 1979. Grassland-herbivore dynamics. In Serengeti: Dynamics of an ecosystem (eds. Sinclair, A.R.E. and M. Norton-
Griffiths). Pp. 46-81. Chicago: The University of Chicago Press.

McNaughton, S.J. and F.F. Banyikwa. 1995. Plant communities and herbivory. In: Serengeti II: Dynamics, management, and conservation of an ecosystem (eds. Sinclair, A.R.E. and P. Arcese). Pp. 49-70. Chicago: University of Chicago press.

Nadasdy, P. 2003. Hunters and bureaucrats: Power, knowledge and aboriginalstate relations in the Southwest Yukon. Vancouver: UBC Press.

Nelson, F., B. Gardner, J. Igoe and A. Williams. 2009. Community-based conservation and Maasai livelihoods in Tanzania. In: Staying Maasai: Livelihoods, conservation and development in east African rangelands (eds. Homewood, K., P. Kristjanson and P. Trench). Pp. 299-333. New York: Springer.

Nelson, F. 2010. Conservation and citizenship: Democratizing natural resource governance in Africa. Policy Matters 17: 233-241.

Neumann, R. 1998. Imposing wilderness: Struggles over livelihood and nature preservation in Africa. Berkeley: University of California Press.

Peterson, R.B., D. Russell, P. West and J.P. Brosius. 2010. Seeing (and doing) conservation through cultural lenses. Environmental Management 45(1): 5-18.

Rangarajan, M. and G. Shahabuddin. 2006. Displacement and relocation from protected areas: Towards a biological and historical synthesis. Conservation and Society 4(3): 359-378.

Redford, K.H. and J.P. Brosius 2006. Diversity and homogenization in the endgame. Global Environmental Change 16: 217-319.

Redford, K.H. and S.E. Sanderson. 2006. No roads, only directions. Conservation and Society 4(3): 379-382.

Ribot, J.C. 1999. Decentralization, participation and accountability in Sahelian forestry: Legal instruments of political-administrative control. Africa 69(1): 23-65.

Reid, R.S., M. Rainy, J. Oguto, R.L. Kruska, M. McCartney, M. Nyabenge, K. Kimani, et al. 2003. People, wildlife and livestock in the Mara ecosystem: The Mara count 2002. Nairobi: International Livestock Research Institute.

Sachedina, H.T. 2008. Wildlife is our oil: Conservation, livelihoods and NGOs in the Tarangire ecosystem, Tanzania. Ph.D. thesis. University of Oxford, Oxford, United Kingdon.

Shetler, J.B. 2007. Imagining Serengeti: A history of landscape memory in Tanzania from earliest time to present. Athens: Ohio University Press.

Sumba, D., P. Bergin and C. Jones. 2005. Land conservation trusts: A case study of Manyara Ranch, Tanzania. AWF Working Papers. Washington, DC: African Wildlife Foundation.

Western, D. and T. Dunne 1979. Environmental aspects of settlement site decisions among pastoral Maasai. Human Ecology 7(1): 75-98.

Worden, J. 2007. Fragmentation and settlement pattern in Maasailand: Implications for pastoral mobility, drought vulnerability, and wildlife conservation in an east African Savannah. Ph.D. Thesis. Colorado State University, Fort Collins, USA.

West, P., J. Igoe and D. Brockington. 2006. Parks and peoples: The social impact of protected areas. Annual Review Of Anthropology 35: 251-277. 